\section{THE STRUCTURE OF RED-INFRARED SCATTERGRAMS \\ OF SEMIVEGETATED LANDSCAPES}

Michael F. Jasinski and Peter S. Eagleson $\therefore A G 5-5 T 0$

MASS

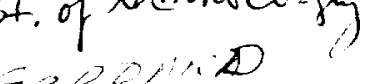
GICINT

ABSTRACT - A physically-based linear stochastic geometric canopy-soil reflectance model is presented for characterizing spatial variability of semivegetated landscapes at subpixel and regional scales. Landscapes are conceptualized as stochastic geometric surfaces, incorporating not only the variability in geometric elements, but also the variability in vegetation and soil background reflectance which can be important in some scenes. The model is used to investigate several possible mechanisms which contribute to the often observed characteristic triangular shape of red-infrared scattergrams of semivegetated landscapes. Scattergrams of simulated semivegetated scenes are analyzed with respect to the scales of the satellite pixel and subpixel components. Analysis of actual aerial radiometric data of a pecan orchard is presented in comparison with ground observations as preliminary confirmation of the theoretical results.

KEYWORDS - Canopy-soil reflectance model, remote sensing, semivegetated landscapes, stochastic processes, subpixel variability, scattergrams, soil line, tasseled cap.

Manuscript received March 10, 1988; revised

The authors are with the Ralph M. Parsons Laboratory for Water Resources and Hydrodynamics, Department of Civil Engineering, Massachusetts Institute of Technology, Cambridge, MA 02139.

Submitted to JEE Trans. Geosci. and Remote Sens., February, 1988.

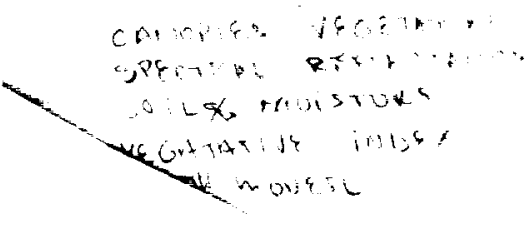




\section{INTRODUCTION}

The physically-based parameterization of heat and moisture fluxes from semivegetated landscapes is an unsolved problem in many mesoscale studies. One difficulty is quantifying state variables (e.g., vegetation cover, soil moisture, surface temperature) which exhibit important spatial and temporal variability at scales smaller than the scale of the measurement. Examples arise in the characterization, using satellite multispectral data, of semivegetated landscapes such as the semiarid regions of the southwest United States and agricultural lands during their early growing stages. In both cases vegetation density varies at characteristic scales (several meters) much smaller than the pixel scale of current satellite multispectral (MSS) sensors (several tens of meters). Pixel scale measurements represent the integrated reflectance of soil and vegetation, and as a result, techniques to disaggregate important subpixel components are warranted.

In addition to subpixel variations, many landscapes exhibit regional variations in soil and vegetation reflectance due to a variety of geoclimatic factors. For instance, changes in slope and aspect induce corresponding changes in scene reflectance through an effective altering in the illumination and viewing angles. Changes in elevation, slope, and aspect also cause scene variability through their indirect influence on such properties as soil moisture, and vegetation species and density. Thus, many soil and vegetation properties which exhibit small random, subpixel scale fluctuations may be spatially correlated at larger geoclimatic scales. Knowledge of that correlation provides valuable insight into the solution of the parameterization problem.

The purpose of this paper is twofold. A first goal is to demonstrate how the subpixel variability ; regionally variable semivegetated landscapes can be 
characterized using a stochastic-geometric canopy reflectance model. The approach is to retain the bulk plant and soil parameters which dominate scene reflectance (fractional cover, plant geometry, and plant and soil reflectance), but to prescribe them as random variates, when necessary, in order to absorb scene variability caused by spatial fluctuations in numerous secondary parameters (leaf area and orientation, surface roughness, soil moisture and organic content). The result is a flexible means of characterizing landscapes without having to specify an inordinate number of parameters which may be of minimal importance to large scale hydrologic processes.

A second goal is to demonstrate the utility of the canopy-soil reflectance model for understanding the information content of multidimensional scattergrams. Specifically, using simulated images, the present work examines the evolution of the two-dimensional (red-infrared) scattergram of semivegetated scenes, and the different possible mechanisms which contribute to its often observed characteristic triangular shape or "tasseled cap" [1]. Additionally, as a preliminary evaluation of this approach, actual aerial radiometric data of a pecan orchard are analyzed in conjunction with a theoretical model of the orchard, and are compared with ground observations. Such understanding is invaluable to the solution of the inverse problem, the estimation of subpixel parameter variability given the observed scattergram.

\section{REFLECTANCE MODELS OF INHOMOGENEOUS CANOPIES}

The reflectance of semivegetated landscapes results from the complex scattering, absorption, and emittance properties of the plant components and soil background. The modeling of this process is difficult, in part, due to the spatial variability of those properties. 
Physically-based radiative transfer models for horizontally homogeneous canopies generally require the estimation of a large number of parameters and extensive data sets (for example, [2], [3], [4], [5]). Regional scale investigations compound the problem due to spatial variations in the landscape. Thus, practical application of the above models using existing satellites is not possible due to the limited data currently available.

An alternative approach to modeling canopy reflectance, applicable to regional scale investigations, is through the use of geometric models. These models, an evolution of early mixed pixel studies [6], conceptualize clumps of vegetation as solid three-dimensional geometric elements superposed on a flat soil background. The distribution of the elements themselves can be geometric, as in the case of row crops, or statistical, as for natural vegetated landscapes.

Geometric models have been successfully used to describe much of the variability of semiregetated landscapes by altering the shape and density of the geometric canopy elements. Otterman [7] modeled forests and desert vegetation as thin vertical cylinders of random height and spacing. Richardson et al. [8] modeled crop canopies as rectangular rows, neglecting scattering between the crop and soil. Jackson et al. [9] extended the above model to inciude shadowed canopy effects. Strabler and $\mathrm{Li}[10]$ and $\mathrm{Li}$ and Strahler [11] modeled conifer forests as randomly located cones of similar shape and random height, assuming constant tree and soil. background reflectances.

The application of geometric models to natural watersheds generally requires assumptions on the statistical distribution of plant spacing. Several authors (see, for example, [12], [13]) have focused on the problem of fitting stochastic models to spatial point patterns of natural (undisturbed) vegetation. Diggle [13] concluded 
that several forest species followed a Poisson distribution or a Poisson cluster process.

Significant progress in incorporating statistical spatial distributions into the analysis of remotely sensed data has only recently been achieved [10], [11], [14]. Li and Strahler [11] and Strahler and $\mathrm{Li}$ [10] assumed a homogeneous Poisson distribution of conifer tree locations. Woodcock [14] used a similar model to examine the relation among the scale of pixel components, resolution size, and two indicators of spatial correlation: the variogram and the local variance.

\section{STOCHASTIC CANOPY REFLECTANCE MODEL}

Many semivegetated landscapes are characterized not only by variations in plant size and density, but also by variations in the reflectance of the vegetation and soil background. Variations in reflectance are brought about by changes in topography and in the physical properties of the plant (e.g., leaf area, amount of chlorophyll) and soil background (e.g., surface roughness, soil moisture). Such variability can have a significant influence on the interpretation of scenes and therefore must be recognized when applying geometric models to regional scale problems.

One method for incorporating the soil and vegetation reflectance variability into geometric modeis is by treating the reflectance terms as random variates. This approach assumes that the overall spatial variability of any one term, for example, illuminated soil reflectance, is a result of the combined variability of numerous physical properties which cannot be easily discerned. The practical advantage of this approach is that it allows one to characterize the spatial variability of the bulk model variates without having to specify numerous parameters which may be of se' ndary importance to the ri ional scale investigation. 
The total reflectance of an individual pixel, $R$, is modeled as an arca-weighted linear combination of the reflectance of four bulk components: illuminated and shadowed canopy, and illuminated and shadowed soil background. It can be expressed in its most general form as

$$
R(\lambda)=m_{I} \bar{R}_{m_{I}}(\lambda)+m_{s} \bar{R}_{m_{s}}(\lambda)+g_{I} \bar{R}_{g_{I}}(\lambda)+g_{S} \bar{R}_{g_{S}}(\lambda)
$$

where $\lambda=$ wavelength,

$$
\begin{aligned}
\overline{\mathrm{R}}_{\mathrm{m}_{\mathrm{I}}}(\lambda)= & \text { average reflectance of illuminated vegetation of a given pixel, } \\
\overline{\mathrm{R}}_{\mathrm{m}_{\mathrm{S}}}(\lambda)= & \text { average reflectance of shadowed vegetation of a given pixel, } \\
\overline{\mathrm{R}}_{\mathrm{g}_{\mathrm{I}}}(\lambda)= & \text { average reflectance of illuminated soil background of a given } \\
& \text { pixel, } \\
\overline{\mathrm{R}}_{\mathrm{g}_{\mathrm{S}}}(\lambda)= & \text { average reflectance of soil background shadowed by canopy of } \\
& \text { a given pixel, } \\
\mathrm{m}_{\mathrm{I}}, \mathrm{m}_{\mathrm{S}}= & \text { percentage of pixel covered with illuminated and shadowed } \\
& \text { canopy, respectively, and } \\
\mathrm{g}_{\mathrm{I}}, \mathrm{g}_{\mathrm{S}}= & \text { percentage of pixel occupied by illuminated and shadowed } \\
& \text { soil background, respectively. }
\end{aligned}
$$

Average reflectances and percent covers are defined, for example

$$
\begin{aligned}
& \overline{\mathrm{R}}_{\mathrm{m}_{\mathrm{I}}}(\lambda)=\frac{1}{\mathrm{~A}_{\mathrm{m}_{\mathrm{I}}}} \int_{\mathrm{Am}_{\mathrm{I}}} \mathrm{R}_{\mathrm{m}_{\mathrm{I}}}(\lambda) \mathrm{dA}_{\mathrm{m}_{\mathrm{I}}} \\
& \mathrm{m}_{\mathrm{I}}=\frac{1}{\mathrm{~A}} \int_{\mathrm{A}} \mathrm{dA}_{\mathrm{m}_{\mathrm{I}}}
\end{aligned}
$$


where $\mathrm{A}=$ total area of a given pixel,

$$
\begin{aligned}
& \mathrm{A}_{\mathrm{m}_{\mathrm{I}}}=\text { total area of a given pixel covered with vegetation } \\
& \mathrm{dA}_{\mathrm{m}_{\mathrm{I}}}=\text { area of smallest homogeneous element of illuminated canopy, }
\end{aligned}
$$

and

$$
\begin{aligned}
\mathrm{R}_{\mathrm{m}_{\mathrm{I}}}(\lambda)= & \text { reflectance of smallest homogeneous element of illuminated } \\
& \text { canopy. }
\end{aligned}
$$

The total percent canopy cover, $\mathrm{m}$, soil background, $\mathrm{g}$, and shadow, $\mathrm{s}$, in a pixel are, respectively,

$$
\begin{aligned}
& \mathrm{m}=\mathrm{m}_{\mathrm{I}}+\mathrm{m}_{\mathrm{s}} \\
& \mathrm{g}=\mathrm{g}_{\mathrm{I}}+\mathrm{g}_{\mathrm{S}} \\
& \mathrm{s}=\mathrm{m}_{\mathrm{s}}+\mathrm{g}_{\mathrm{S}}
\end{aligned}
$$

where

$$
\mathrm{m}_{\mathrm{I}}+\mathrm{m}_{\mathrm{S}}+\mathrm{g}_{\mathrm{I}}+\mathrm{g}_{\mathrm{S}}=1
$$

In a stochastic-geometric model, all the terms in equation (1) can be treated as random rariates, if necessary, depending on the nature of the scene. That is, ther can be characterized with respect to their mean, variance, anc, in some cases, a spatial covariance. Additionally, there may exist cross covariances between the various terms. For example, the vegetation reflectance $\bar{R}_{m_{I}}(\lambda)$ may depend on the percent vegetation cover, $m_{I}$, or on the soil background reflectance, $\bar{R}_{g_{I}}(\lambda)$. Also, for large-scale pixels, the fractional covers will be correlated (see Case IV, latèr in this report).

\section{SOIL REFLECTANCE}

Soil background reflectance often exhibits high variability in semivegetated scenes. It varies over a wide range of length scales due $t$, changes in the physical . 
structure and chemical composition of the near surface soil. Small-scale perturbations (meters or less) occur with changes in mineral content, water and organic matter content, particle size, soil texture and surface roughness. Numerous experimental investigations have examined the relationship between bare soil reflectance and those parameters (for a summary, see Myers [15]).

Soil reflectance also varies at larger geophysical scales. For example, the presence of hills will change soil reflectance due to an effective altering of the illumination and viewing angles. Changes in elevation, slope, and aspect will influence soil moisture and organic matter content. Subsurface variations in geologic formations will affect mineral content. Those geophysical factors impose a spatial correlation to soil reflectance at scales of 10 to $10^{3}$ meters.

In addition to spatial correlations, soil reflectance can also be cross-correlated at different wavelengths. These wavelength dependent correlations are manifested in multispectral scattergrams of real scenes through the preferred location and orientâtion of bare soil pixels (see, for example, [1], [16], [17\}). For red-infrared scattergrams of typical semivegetated scenes, the data often take on the form of a triangle whose base consists of a straight line emanating from approximately the origin. Researchers have identified that base line, consisting primarily of pixels containing bare soil and dry vegetation, as the "soil line".

Analysis of previously published theoretical and experimental studies (for example [18], [19], [20], [21]) indicates that for a given type of soil variability, the soil reflectance at one wavelength is often functionally related to the reflectance in another wavelength. In many cases, the relation can be approximated by a simple linear expression

$$
\mathrm{R}\left(\lambda_{2}\right)=\alpha \mathrm{R}\left(\lambda_{1}\right)+\gamma
$$


where the slope, $\alpha$, and intercept, $\gamma$, are coefficients dependent on both the wavelength and the type of variability. Thus, variability of any one soil parameter can lead to a representative "line" in a two-dimensional scattergram.

For instance, Figure 1 contains three hypothetical visible-infrared scattergrams, representing three different scenes, in each of which only one soil parameter is allowed to vary. In Scene 1 only the amounts of two minerals are allowed to vary, while all other soil parameters such as surface roughness, moisture, etc. are held constant. The resulting scattergram forms a "soil mineral line" in which the end points approach the respective reflectances of the pure minerals. The shape and orientation of the line may be linear (as drawn) or nonlinear, and are determined by the location of the end points and the nature of the mixing of the two mineral types [22]. Pixels lying between the end points will contain mineral amounts proportional to their distance along the line.

Scene 2 contains hypothetical pixels in which only soil moisture is allowed to vary. Soil moisture increases the radiation absorption capacity of the soil in the visible and near infrared regions. Analysis of published experimental data [20i, [21], indicates that, for many soil types, equation ( 8 ) is applicable. Thus the locus of points for Scene 2 pixels should form a "soil moisture line" as indicated in Figure 1 with the pixels along the left portion of the line containing higher soil moisture than those to the right.

Finally, Scene 3 contains pixels in which only surface roughness varies. Soil' reflectance generally decreases with increased surface roughness due to the increase in shadow cast by the soil particles and aggregates onto itself [15], [18]. The resulting "soil shadow line" is approximately linear with an intercept of near zero. The linearity occurs since the amount of shadow caused by the soil aggregates is 
practically the same for the range of wavelengths being considered. In fact, a near zero intercept for straight soil lines of real scenes (with low diffuse radiation) may be an indication that soil shadow induced by its physical structure is the dominant source of soil reflectance variability.

In actuality, real soil scenes contain a composite of several types of variability. The corresponding soil line is generally linear in the mean although considerable scatter can exist [1], [16]. A unique soil line will exist only if either 1) one dominant type of soil variability is occurring or 2) the scatter due to the different types of soil variability act in the same direction.

\section{RED-INFRARED SCATTERGRAMS OF SEMIVEGETATED LANDSCAPES}

One application of the stochastic-geometric canopy reflectance model is the investigation of the structure, or physical basis, of red-infrared scattergrams of semivegetated landscapes. That is achieved by using the model with typical values to simulate different scenes, and then comparing the shape and common features of the corresponding red-infrared scattergrams. An understanding of the influence of a given random variable is obtained by altering one of its statistics (e.g., variance), while holding all others constant.

The following section presents the results of five different simulations. The input values of the different model variables are provided in Table 1. While those scenes represent only a few selected scenarios, they were chosen to demonstrate the important general relationship between the main model variables and their effect on the scattergram. 
Scenes are generated as follows. A scene consists of eight segments, each 150 meters square with one meter square pixels. Each segment within a scene is assigned an identical soil background reflectance distribution. Next, trees represented by square cylinders of fixed height and canopy arca are superposed on the soil background of each segment according to a Poisson distribution having a different arrival rate for each segment. The shadowed portions of the scene are then determined. Typical values of soil and vegetation reflectance are assumed [2], [15], [19] as indicated in Table 1. Finally, the original grid is aggregated to pixel sizes of 5,10 , and 30 meters square by averaging the reflectance values of the components of the grid. The latter two represent SPOT and Thematic Mapper satellite scales, respectively. Information regarding subpixel variables is recorded at each level of aggregation.

\section{A. CASE I - CONSTANT REFLECTANCES, NO SHADOWS}

This case represents an idealized two-component sivuation in which the regetation and soil each have a constant refiectance over the entire scene, and obserrations are from the nadir. The sun is near zenith resulting in no shadows in the field of view. Hence, the only random variable is percent cover. The equation expressing total refleciance from an incividual pixel is taken from equâtions (1) through ( $\bar{i}$ ) with $\mathrm{m}_{\mathrm{S}}=\mathrm{g}_{\mathrm{S}}=0$, or

$$
\mathrm{R}(\lambda)=m R_{m_{\mathrm{I}}}(\lambda)+(1-\mathrm{m}) \mathrm{R}_{\mathrm{g}_{\mathrm{I}}}(\lambda)
$$

The visible-infrared scattergrams for the Case 1 simulation are shown in Figures 2-a,b,c for the levels 5, 10, and 30 aggregation. They indicate that all the data points fall on a straight line whose end points represent pixels containing the 
maximum (upper left) and minimum (lower right) percent vegetation cover within the scene. The length of the line decreases with increasing aggregation since the standard deviation of the canopy density decreases as the pixel size increases. The percent cover of any pixel lying along the line is proportional to the distance between the end points.

\section{B. CASE II - VARIABLE SOIL REFLECTANCE, NO SHADOW'S}

In addition to changing vegetation cover, the Case II simulation includes the effect of spatial variability of soil reflectance. Both small scale (subpixel) and large scale (regional) variations are incorporated by treating soil reflectance as a two-dimensional random field with a prescribed covariance structure.

While various functional forms might be applicable, for demonstration purposes, the Case II simulation assumes that soil reflectance is normally distributed with an exponential covariance function. It is expressed

$$
\operatorname{cov}(\mathrm{d})=\sigma^{2} \exp (-3 \mathrm{~d})
$$

where

$$
\begin{aligned}
& \sigma^{2}=\text { the variance of the soil reflectance distribution. } \\
& \beta=\text { inverse length scale of the corariance function, and } \\
& \mathrm{d}=\text { distance between two points in the scene. }
\end{aligned}
$$

The simulated bare soil scene for the red band is shown in Figure 3. That scene, generated using the Turning Bands Method [23], contains a mean reflectance (0.15), standard deviation (0.023), and exponential covariance. A similar scene (not shown) was generated for the infrared band. The mean and standard deviations of both scenes are based on the hypothetical soil reflectance curve shown in Figure 4, 
which indicates a typical range of reflectances for a soil with variable properties (e.g., soil moisture or surface roughness) [15], [20].

The length scale of the exponential covariance function was chosen to be 20 meters. While that might represent some geophysical scale, for the present case it is chosen for convenience. It is much larger than the grid scale of one meter, and the two smaller aggregations ( 5 and 10 meters), but smaller than the largest aggregation (30 meters). Thus, the choice of that scale allows one to examine the relation between covariance length scale and pixel size.

The total reflectance from a given pixel in the Case II simulation is,

$$
\mathrm{R}(\lambda)=\mathrm{mR}_{\mathrm{m}_{\mathrm{I}}}(\lambda)+(1-\mathrm{m}) \overline{\mathrm{R}}_{\mathrm{g}_{\mathrm{I}}}(\lambda)
$$

The results of the Case II simulation for all three aggregations are show in Figures 5-a,b.c. (Regular spaces in the scattergrams, especially at lower level aggregations, are due to finite increments in percent cover as limited by the level of aggregation. This effect occurs in subsequent cases as well.) They indicate that the red-infrared scattergram tends to take on the characteristic shape of a triangle. The top of the triangle represents full canopy cover, and the base represents the minimum vegetation cover in the scene. For areas in which it can be assumed that bare soil exists, the base of the triangle represents the classic "soil line."

While Case II is still a relatively simple example, it demonstrates, the usefulness of the scattergram for explaining subpixel variability. For instance, all pixeis falling on a line parallel to the soil line will have the same percent vegetation. A second observation is that all pixels falling on a straight line extending from the top of the triangle to the soil line will bave the same value of 
average soil reflectance. The above interpretations of the scattergram are indicated on Figure 6 (an expanded version of $5 \mathrm{~b}$ ) for the level 10 aggregation.

The importance of pixel scale relative to the covariance function is seen in the size of the triangles at different levels of aggregation. The scattergrams indicate that the length of the soil line and hence the width of the triangle decrease with increasing aggregation. Both the standard deviation and the covariance length scale contribute to that effect. Since scenes composed of large pixels average over a greater area than scenes with small pixels, statistically, one can expect the former case to have a lower standard deviation. However, that effect is mitigated by the covariance length scale. Scenes with small length scales (relative to pixel size) will exhibit short soil lines while scenes with large length scales will exhibit long soil lines.

\section{CASE III - VARIABLE VEGETATION REFLECTANCE, NO SHADOWS}

In addition to rariable percent cover and variable soil refiectance. the Case III simulation introduces variable vegetation reflectance and examines its effect on the reci-infrared scattergram. Vegetation reflectance will change at small and large spatial scales due to variations in a number of plant parameters, including plant species, leaf reflectance, growth stage, plant architecture, leaf orientation and distribution, leaf area, and plant stress [2]. Regional scale variations in the pattern of natural vegetation and dominant species are influenced by elevation, gradient, and local climate [12].

As for soil, Case III treats the variation in vegetation reflectance as a normally distributed random variable with an exponential covariance structure. It further assumes that reflectances in the infrared and visible bands are linearly related with negative slope. That relationship is not intended to represent all types of vegetation variability, but may be a simple approximation for some cases. For instance, 
increases in leaf area are generally associated with decreases in visible reflectance and increases in infrared reflectance (see for example, [24]. [25]).

For Case III, the total reflectance of a given pixel becomes

$$
R(\lambda)=m \bar{R}_{m_{I}}(\lambda)+(1-m) \bar{R}_{g_{I}}(\lambda)
$$

where the three random variables are percent cover $(\mathrm{m})$, vegetation reflectance $\left(\overline{\mathrm{R}}_{\mathrm{m}_{\mathrm{I}}}\right)$ and soil reflectance $\left(\overline{\mathrm{R}}_{\mathrm{g}_{\mathrm{I}}}\right)$.

The scattergram for Case III is presented in Figures $7-a, b, c$ for all levels of aggregation. The difference from Case II is that the top of the triangle has spread open, resulting in a quadrilateral data plot. An envelope curve along the top of the quadrilateral represents pixels of maximum vegetation cover. For scenes containing full canopy cover, that locus of points can be considered the "canopy line" analogous to the soil line at the base of the quadrilateral.

It is noted that for all three non shadowed cases (I, II, and III), neither plant geometry nor spatial distribution play a role in the shape of the scatiergram or the relative location of a given pixel. Similar scattergrams could have been achieved using any plant geometry (e.g., spheres or cones) or spatial distribution (e.g., row crops with any orientation) as long as the distribution of the reflectances and the percentage of vegetation cover were the same.

D. CASE IV - SHADOWED SOIL BACKGROUND, CONSTANT 、 VEGETATION AND SOIL REFLECTANCE

Shadows cast by vegetation can be an important component of total pixel reflectance. Shadows change diurnally with the position of the sun and with the 
amount of diffuse solar radiation. Important seasonal changes occur both with the sun's migration and with changes of plant structure.

Case IV examines the effect of shadows cast by plants on soil. The solar and view angles are arbitrarily assumed to be $30^{\circ}$ and $0^{\circ}$, respectively, and the reflectances are constant. The reflectance equation for a given pixel is

$$
R(\lambda)=m R_{m_{I}}(\lambda)+g_{I} R_{g_{I}}(\lambda)+g_{S} R_{g_{S}}(\lambda)
$$

The scattergrams associated with the three aggregation levels for the Case IV simulation are shown in Figures 8-a,b,c. They reveal several interesting relations among percent cover and shadow, the level of aggregation, and the characteristic shape of the scattergram.

All the data pairs fall within a space defined by a triangle. This is illustrated using the level 5 aggregation as indicated in Figure 9 (an expanded version of 8a). The rertices of the triangle (labeled Points B, C, and D) correspond to the assumed pure spectra of the full shadow (reflectance $=0.0$ ), full canopy, and pure soil, respectively, as indicated in Table 1.

Since pixels located within the triangle are linear mixtures of the three cover types, the exact percentage of any cover type can be determined on the basis of its location in the scattergram. For instance, the percent covers for an arbitrary pixel A shown on Figure 9 can be determined graphically as follows. First, lines EF and. GH are drawn through pixel $A$ parallel to $C D$ and $B D$, respectively. It is then noted that line EF is located about one-third of the distance between the line $C D$ and point $B$. That indicates that pixel $A$ contains 33 percent shadow. Line $G H$ is situated about one-fourth the distance between the line $\mathrm{BD}$ and point $\mathrm{C}$, indicating that pixel $\mathrm{A}$ has 25 percent vegetation cover. The remaining cover, 42 percent, is 
bare soil, which can be checked on the basis of pixel A's location between line $\mathrm{BC}$ and point $\mathrm{D}$.

The above determination of the three cover types is simply a graphical illustration of an analytical solution applicable within the limits of the Case IV assumptions. It can be applied to any level of aggregation. The solution could also be achieved algebraically using equation (13) for both wavelengths (two equations) and equation (8).

The Case IV scattergrams also reveal an important relation between shadow length scale and pixel size. For instance, at the level 5 aggregation, since the length scale of the shadow is about the same as the pixel scale, there are numerous instances when the shadow of a tree in one pixel falls onto an adjacent pixel. The three components of the pixel (vegetation, shadowed soil and illuminated soil) are independent of each other in a majority of cases. As a result, pixels can occupy almost any space within the limits of the triangular scattergram given a large enough sample size.

As the level of aggregation increases, however, the length scale of the shadows becomes much smaller than the size of the pixel. As a result, shadows associated with a given tree fall increasingly within the same pixel and the amount of ground shadow becomes more and more correlated with the amount of vegetation cover. Mathematically, a covariance is generated among the three cover variables for the higher levels of aggregation which can be expressed,

$$
\begin{aligned}
& \mathrm{g}_{\mathrm{S}}=\mathrm{g}_{\mathrm{S}}(\mathrm{m}) \\
& \mathrm{g}_{\mathrm{I}}=\mathrm{g}_{\mathrm{I}}(\mathrm{m})=1-\mathrm{m}-\mathrm{g}_{\mathrm{S}}(\mathrm{m})
\end{aligned}
$$

and equation (12) becomes 


\section{ORIGINAL PAGE IS \\ OF. POOR QUALITY}

$$
R(\lambda)=R\left[\lambda, m, g_{I}(m), g_{S}(m)\right]
$$

A major consequence of the above relations is that it reduces the feasible region in the scattergram. Even at the level 5 aggregation (Figure 8a), that effect is manifested as a slight indentation in the upper right hand side of the triangular scattergram. At higher levels of aggregation, Equation (16) implies that there is only one position in the scattergram associated with a given canopy cover. As a result, one should expect the triangular scattergram observed at the level 5 aggregation to collapse to a single curved line when the shadow length scale becomes small relative to the pixel size. That is indeed shown to be true in a progressive manner by examining the sequential shapes of the scattergrams in Figure $8 \mathrm{~b}$ (level 10 aggregation) and Figure $8 \mathrm{c}$ (level 30 aggregation).

\section{E. CASE V-SHADOWED SOIL BACKGROUND, VARIABLE SOIL REFLECTANCE}

Case $\mathrm{V}$ is a more realistic version of the shadow model in which soil reflectance is assumed normally distributed as in Case II. The governing equation for an individual pixel is

$$
\mathrm{R}(\lambda)=\mathrm{mR}_{\mathrm{m}_{\mathrm{I}}}(\lambda)+\mathrm{g}_{\mathrm{I}} \overline{\mathrm{R}}_{\mathrm{g}_{\mathrm{I}}}(\lambda)+\mathrm{g}_{\mathrm{S}} \mathrm{R}_{\mathrm{g}_{\mathrm{S}}}(\lambda)
$$

The resulting scattergrams for the different levels of aggregation are shown in Figure 10.

The scattergrams of the Case V simulation represent a combination of the effects illustrated in Case II (constant vegetation reflectance, variable soil reflectance) and Case IV (shadow effects). 


\section{ORIGINAL PAGE is \\ OF POOR QUALITY}

For instance, the scattergram of the level 5 aggregation, Figure 10a, exhibits a triangular shape overall, but with a pronounced indentation in the upper right portion due to the shadow effects. It can be regarded as a superposition of many triangular scattergrams, each for a homogeneous soil (constant background reflectance), similar to that of Case IV, level 5 aggregation (Figure 9). That is illustrated in Figure 11 (expanded version of 10a). Those triangles share two common vertices at 1) the point of pure shadow reflectance (point B), and 2) the point of pure vegetation reflectance (point $C$ ). The third vertex (labeled $D_{1}, D_{2}, D_{3}$, ... etc.) is unique for each triangle, representing the reflectivity of a particular soil which is homogeneous at that aggregation. The collection of all vertices, D, constitutes the true soil line.

In the particular example shown, the true soil line has an intercept greater than zero, and is thus situated slightly inside the boundaries of the overall scattergram, as indicated in Figure 11. It is also possible, however, that the shadowed soil reflectance lies above the soil line. Only in such cases will the bottom of the scattergram accurately represent the true soil line.

An important consequence of the level 5 aggregation is that pixels containing different mixtures of vegetation, shadow, and variable soil can occupy the same location in the scattergram. As a result, the percent cover of individual pixels can not be determined explicitly as shown in previous examples.

The scattergrams of the levels 10 and 30 aggregation are shown in Figures $10 \mathrm{~b}$ and $10 \mathrm{c}$, respectively. As in Case $\mathrm{N}$, because of the unique relation between shadow and vegetation cover at this scale, the scattergrams collapse progressively to the shape of a "tasseled cap" [1]. At the level 30 aggregation, the scattergram consists of a series of juxtaposed curved lines, each line possessing constant average soil reflectivity ( nilar to Case IV, level 30 aggregation, Figure $8 c$ ), extending from 


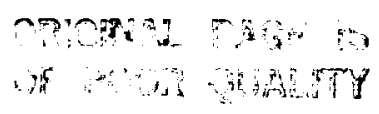

individual points on the true soil line to the tip of the tasseled cap. That is illustrated in Figure 12 (expanded version of 10c).

Unlike the level 5 aggregation, percent cover can be estimated for Case $V$, level 30 aggregation, in a manner similar to Cases II and IV. Percent cover is proportional to the distance between the soil line and the tip of the tasseled cap.

\section{SCATTERGRAM OF A PECAN ORCHARD}

This section applies the canopy model to a pecan orchard for which actual aerial radiometric observations have been obtained. A comparison is made between the plots of the radiometric data in the red-IR reflectance space, and a hypothetical scattergram constructed from ground truth measurements at the time of overflight.

The study site is located near Maricopa, Arizona, about $40 \mathrm{~km}$ south of Phoenix. Aerial radiometric measurements were collected at 9:30 a.m. on June 12, 1988, as part of the MAC III experiment organized by the Water Conservation laboratory, Agricultural Research Service, Phoenix, Arizona. Radiometric observation were made using an Exotech radiometer with Thematic Mapper red $(0.62-0.69 \mu \mathrm{m})$ and IR $(0.78-0.90 \mu \mathrm{m})$ filters at a ground resolution of about 40 meters.

The hypothetical scattergram is obtained by first conceptualizing the orchard as a stochastic geometric surface. The orchard represents a special case in which the trees are spatially distributed in a fixed geometric fashion, and the only random variable is the soil reflectance. The size of the trees and thus the amount of canopy cover, can vary from pixel to pixel.

Ground truth measurements taken at the time of overflight indicate that the trees can be represented as circular cylinders, equally spaced on a square grid, with 
an east-west orientation. The average ratio of canopy diameter to height is equal to about unity. Tree height is generally constant in any given section of the orchard, and thus trees are not shadowed by adjacent trees.

Since the length scale of the ground shadow is much smaller than the scale of the pixel, the above configuration leads to a unique analytical relationship among the fractional covers as described in Section V.E. For the particular orchard described above, two different shadow regimes can be identified. Regime I occurs when the trees are small and the entire shadow cast by a tree is observed. In this case the fractional shadowed area $g_{S}$ is linearly related to the fractional canopy cover, $m$ or

$$
\mathrm{g}_{\mathrm{S}}=\frac{4 \mu \mathrm{m}}{\pi \mathrm{f}} ; \quad \text { for } 2 \sqrt{\frac{\mathrm{m}}{\pi}}\left[1+\frac{\mu}{\mathrm{f}}\right]-1<0
$$

where $\mu$ equals the tangent of the zenith angle and $f$ is a similarity parameter equal to the ratio of canopy diameter to tree height. Regime II occurs for larger trees when the shadow cast by one tree extends far enough as to be overlapped, in part, by the canopy of an adjacent tree. A second term is added to the above equation to account for that decrease in shadowed area, or

$$
\begin{array}{r}
g_{S}=\frac{4 \mu \mathrm{m}}{\pi \mathrm{f}}-2\left\{\frac{\mathrm{m}}{\pi} \cos ^{-1}\left[\frac{1}{2} \sqrt{\frac{\pi}{\mathrm{m}}}-\frac{\mu}{\mathrm{f}}\right]-\left[\frac{1}{2}-\frac{\mu}{\mathrm{i}} \sqrt{\frac{\mathrm{m}}{\pi}}\right]\right. \\
\left.\cdot\left[\left[\left[1+\frac{\mu}{\mathrm{f}}\right] \sqrt{\frac{\mathrm{m}}{\pi}}-\frac{1}{2}\right]\left[\sqrt{\frac{\mathrm{m}}{\pi}}\left[1-\frac{\mu}{\mathrm{f}}\right]+\frac{1}{2}\right]\right]\right\} \\
\text { for } \quad 0<2 \sqrt{\frac{\mathrm{m}}{\pi}}\left[1+\frac{\mu}{\mathrm{f}}\right]-1 \leq 2 \sqrt{\frac{\mathrm{m}}{\pi}}
\end{array}
$$


In both regimes, the illuminated soil is constrained by

$$
\mathrm{g}_{\mathrm{I}}=1-\mathrm{m}-\mathrm{g}_{\mathrm{S}}
$$

The graphical forms of $g_{S}$ and $g_{I}$ are given in Figure 13 .

Also plotted on Figure 13 are the actual fractional cover estimates of several pixels obtained from aerial video. The plots indicate that the theoretical curves of the fractional shadow and illuminated soil agre reasonably well with the actual data.

The hypothetical reflectance of a pixel is described by

$$
\mathrm{R}(\lambda)=\mathrm{mR} \mathrm{m}_{\mathrm{I}}(\lambda)+\mathrm{g}_{\mathrm{S}} \mathrm{R}_{\mathrm{g}_{\mathrm{S}}}(\lambda)+\mathrm{g}_{\mathrm{I}} \overline{\mathrm{R}}_{\mathrm{g}_{\mathrm{I}}}(\lambda)
$$

where $R_{m_{I}}(\lambda), R_{g_{S}}(\lambda)$ and $\bar{R}_{g_{I}}(\lambda)$ represent ground truth reflectances of the illuminated canopy, shadowed soil, and illuminated soil, respectively. Since no treeless pixels existed in the orchard itself, the soil reflectance was obtained by sensing fields immediately adjacent to the orchard which contained a mixture of bare soil and senesced grasses. The soil line obtained from a red-infrared plot of the data is shown in Figure 14. The line exhibits a nearly linear relationship as described in Section IV and equation (8). The mean, standard deviation, and corariance length scale (computed as the average e-folding distance of the empirical correlation function) of those soil pixels, together with the parameters of the soil line areprovided in Table 2.

Ground truth values of the pecan canopy's bulk reflectance could not be easily obtained due to the large size of the trees. However, the aerial data indicate that 
the bulk canopy reflectance is about $2-4 \%$ in the red band and $45-55 \%$ in the IR band. The mid-points of those values (canopy red reflectance $=3.0 \%$; canopy IR reflectance $=50 \%$ ) were arbitrarily chosen as estimates of the canopy reflectances. Shadowed reflectances were assumed to equal $10 \%$ of the canopy reflectances.

Using (17) through (20), a hypothetical orchard scene was constructed by superposing canopy cover ranging from 10 to 70 percent onto each of the soil background pixels. The resulting scattergram based on that model is shown in Figure 14. It possesses many similarities to the simulated cases presented earlier, including a triangular shape with curved sides and a flat base.

Also plotted on Figure 14 are several radiometric data for which the subpixel fractional covers are known. The orchard itself does not possess a wide range of vegetation cover needed to establish a complete triangular scattergram. However, a comparison of the actual data with the hypothetical scattergram indicates that their location is consistent with the predicted values. A summary of the actual and hypothetical fractional covers for four pixels is provided in Table 3. The good agreement achieved above serves as a preliminary confirmation of the validity of the stochastic model for explaining how subpixel variations in cover type affect the relative location of pixels in a red-infrared scattergram.

\section{SLMMARY}

This report has presented a flexible, physically-based approach for characterizing the spatial variability of semivegetated regions by modeling' the landscape as a stochastic geometric surface. The reflectance model is intended for regional scale investigations in which the parameterization of numerous plant and soil properties is infeasible. By absorbing the variability of such properties into a few bulk plant and soil variables, an inb ent tradeoff is made between the amount 
of physical detail which can be modeled and the size of the region which can be investigated.

The utility of the canopy reflectance model for understanding the physical basis of red-infrared scattergrams has been demonstrated by examining five different stochastic landscapes in a progressive manner. By altering only one of the bulk model variables at a time, the theoretical contribution of each of them toward the evolution of the typical triangular shape of red-infrared scattergrams has been examined. The model has also been shown to be a viable mechanism for understanding the sensitivity of the scattergram to such factors as the scale of the pixel, and the scale of the subpixel elements. One example is the explanation of the existence of the tasseled cap which has been shown, at least in part, to be a manifestation of the covariance which exists between cover types when the scale of the pixel is much greater than the shadow length scale.

A potential application of the model is the solution to the inverse problem, the estimation of subpixel parameters given an actual scattergram. That research application is currently under way and will be summarized in a subsequent report.

\section{ACKNOWLEDGEMENTS}

This work was performed with the support of the NASA Goddard Space Flight Center under Grant NAG $j-510$.

The authors wish to thank Dr. Ray Jackson and Susan Moran, Water Conservation lab, Agricultural Research Service, Phoenix, AZ and David S. Ammon, Aerial Images, Tucson, for their help in acquiring the aerial data and in converting the radiometric measurements to reflectances. 


\section{REFERENCES}

[1] R. J. Kauth and G. S. Thomas, "The Tasselled Cap-A Graphic Description of the Spectral-Temporal Development of Agricultural Crops as Seen by Landsat," Proc. of the Symp. on Machine Processing of Remotely Sensed Data, Purdue Univ., W. Lafayette, IN, pp. 4B41-4B51, 1976.

[2] J. Ross, The Radiation Regime and Architecture of Plant Stands, Dr. W. Junk, Publishers, The Hague, 1981.

[3] G. H. Suits, "Calculation of the Directional Reflectance of a Vegetation Canopy," Remote Sensing of Environment, Vol. 2, pp. 117-125, 1972.

[4] W. Verhoef, and N. J. J. Bunnik, "Influence of Crop Geometry on Multispectral Reflectance Determined by Use of Canopy Reflectance Models," Proceedings of the International Colloquium on Signatures of Remotely Sensed Objects, Avignon, pp. $273-290,1981$.

[5] N. S. Goel and R. L. Thompson, "Inversion of Vegetation Canopy Reflectance Models for Estimating Agronomic Variables. III. Estimation Using Only Canopy Reflectance Data as Mlustrated by the Suits Model," Remote Sensing of Environment, Vol. 15, pp. 223-236, 1984.

[6] H. M. Horwitz, R. F. Nalepka, P. D. Hyde, and J. P. Morgenstern, "Estimating the Proportions of Objects within a Single Resolution Element of a Multispectral Scanner," Proceedings of the 6th International Symposium on Remote Sensing of Environment, Willow Run Labs, The University of Michigan, Ann Arbor, MI, pp. 1307-1320, 1971.

[7] J. Otterman, "Albedo of a Forest Modeled as a Plane with Dense Protrusions," Journal of Climate and Applied Meteorology, Vol. 23, February, pp. 297-307, 1984. 
[8] A. J. Richardson, C. L. Wiegand, H. W. Gausman, J. A. Cuellar, and A. H. Gerbermann, "Plant, Soil, and Shadow Reflectance Components of Row Crops," Photogrammetric Engineering and Remote Sensing, Vol. 41, No. 11, pp. 1401-1407, 1975.

[9] R. D. Jackson, R. J. Reginato, P. J. Pinter, and S. B. Idso, "Plant canopy information extraction from composite scene reflectance of row crops," Applied Optics, Vol. 18, No. 22, pp. 3775-3782, 1979.

[10] A. H. Strahler and $\mathrm{Li}$ Xiaowen, "An Invertible Coniferous Forest Canopy Reflectance Model," Proceedings of Fifteenth International Symposium on Remote Sensing of Environment, Ann Arbor, MI, pp. 1237-1244, 1981.

[11] X. Li and A. H. Strahler, "Geometric-Optical Modeling of a Conifer Forest Canopy," IEEE Transactions on Geoscience and Remote Sensing, Vol. GE-23, No. 5, pp. $705-721,1985$.

[12] R. H. Whittaker, Communities and Ecosystems, 2nd Edition, Macmillan Publishing Co., New York, 1975.

[13] P. J. Diggle, Statistical Analysis of Spatial Point Patterns, Academic Press, New York, 1983.

[14] C. E. Woodcock, Linderstanding Spatial Variation in Remotely Sensed Imagery, Ph.D. Dissertation, Liniversity of California, Santa Barbara, 1985.

[15] V. I. Myers, "Remote Sensing Applications in Agriculture," in Manual of Remote Sensing. American Society of Photogrammetry, Chapter 33, pp. 2111-2228, 1983.

[16] A. J. Richardson and C. L. Wiegand, "Distinguishing Vegetation from Soil Background Information," Photogrammetric Engineering and Remote Sensing, Vol. 43, No. 12, pp. 1541-1552, 1977. 
[17] A. R. Huete, R. D. Jackson and D. F. Post, "Spectral Response of a Plant Canopy with Different Soil Backgrounds," Remote Sensing of Environment, Vol. 17, pp. 37-53, 1985.

[18] J. Cierniewski, "A Model for Soil Surface Roughness Influence on the Spectral Response of Bare Soils in the Visible and Near-Infrared Range," Remote Sensing of Environment, Vol. 23, pp. 97-115, 1987.

[19] J. A. Smith, "Matter-Energy Interaction in the Optical Region," in Manual of Remote Sensing, American Society of Photogrammetry, Chapter 3, pp. 61-113.

[20] S. A. Bowers and R. J. Hanks, "Reflection of Radiant Energy from Soils," Soil Science, Vol. 100, No. 2, pp. 130-138, 1965.

[21] E. L. Skidmore, J. D. Dickerson and H. Schimmelpfennig, "Evaluating Surface-Soil Water Content by Measuring Reflectance," Soil Sci. Soc. Amer. Proc., Vol. 39, pp. 238-242, 1975.

[22] M. D. Smith. P. E. Johnson, and J. B. Adams, "Quantitative Determination of Mineral Types and Abundances from Reflectance from Reflectance Spectra Using Principal Components Analysis," Proc. 15th Lunar and Planetary Science Conference, Part 2. J. of Geoph. Res., Vol. 20. Supplement, pp. C79i-C804, 1985.

[23] A. Mantoglou and J. L. Wilson, "The Turning Bands Method for Simulation of Random Fields Using Line Generation by a Spectral Method," Water Resources Research, Vol. 18, No. 5, pp. 1379-1394, 1982.

[24] J. E. Colwell, "Vegetation Canopy Reflectance," Remote Sensing of Environment, Vol. 3, pp. 175-183, 1974.

[25] F. Hall, "Remote Sensing of Vegetation at Regional Scales," Proc. Soc. Photo-Optical Instrum. Eng., Vol. 475, pp. 81-96, 1984. 


\section{Figure Captions}

Figure 1.

Figure 2-a,b,c.

Figure 3.

Figure 4.

Figure 5-a,b,c.

Figure 6.

Figure 7-a,b,c.

Figure 8-a,b,c.

Figure 9.

Figure 10-a,b,c.

Figure 11.

Figure 12.

Figure 13.

Figure 14.
Hypothetical soil lines.

Red-infrared scattergrams, Case I simulation: variable percent cover, constant soil and vegetation reflectances; no shadows.

Hypothetical segment of bare soil scene, visible band.

Hypothetical soil reflectance curve.

Red-infrared scattergrams, Case II simulation: variable percent cover and soil reflectance, constant vegetation reflectance; no shadows.

Interpretation of scattergram, Case II simulation, level 10 aggregation: variable percent cover and soil reflectance, constant vegetation reflectance; no shadows.

Red-infrared scattergrams, Case III simulation: variable percent cover, soil and vegetation reflectances; no shadows.

Red-infrared scattergram, Case IV simulation: variable percent cover, constant soil and vegetation reflectances; shadowed soil background.

Interpretation of scattergram, Case IV simulation, level 5 aggregation: variable percent cover, constant soil and vegetation reflectances; shadowed soil background.

Red-infrared scattergrams, Case $V$ simulation: variable percent cover and soil reflectance, constant vegetation reflectance; shadowed soil background.

Interpretation of scattergam, Case $V$ simulation, level 5 aggregation: variable percent cover and soil reflectances, constant vegetation reflectance; shadowed soil background.

Interpretation of scattergram, Case $V$ simulation, level 30 aggregation: variable percent cover and soil reflectance, constant vegetation reflectance; shadowed soil background.

Theoretical relationship of percent illuminated soil, $\mathrm{g}_{\mathrm{I}}$, and percent shadowed soil, $g_{s}$, as a function of percent canopy cover, $\mathrm{m}$, compared to actual data for a pecan orchard.

Hypothetical scattergram of pecan orchard compared with actual aerial radiometric data. 
Michael F. Jasinski received his B.S. in civil and environmental engineering, and his M.S. in hydrology, both from Cornell University, in 1974 and 1976, respectively. He subsequently served two years in the U.S. Peace Corps in West Africa as a water projects engineer. From 1978 through 1984 he worked for Harza Engineering Company, Chicago on foreign and domestic water resources projects and environmental impact analyses. He is currently pursuing his Ph.D. at Massachusetts Institute of Technology specializing in the field of hydroclimatology.

\section{Autobiography of Peter S. Eagleson}

Peter S. Eagleson was born in Philadelphia, PA in 1928. He received the B.S. and M.S. degrees in Civil Engineering from Lehigh University in 1949 and 1952, respectively and the Sc.D., with a fluid mechanics concentration, from MIT in 1956.

Since 1955 he has been a faculty member of the Department of Civil Engineering at MII where his research interests have evolved from coastal processes and hydro-elastic vibrations to surface water hydrology. Most recently his work has focused on the parameterization of hydrologic processes, including vegetation communities, within atmospheric general circulation models. 


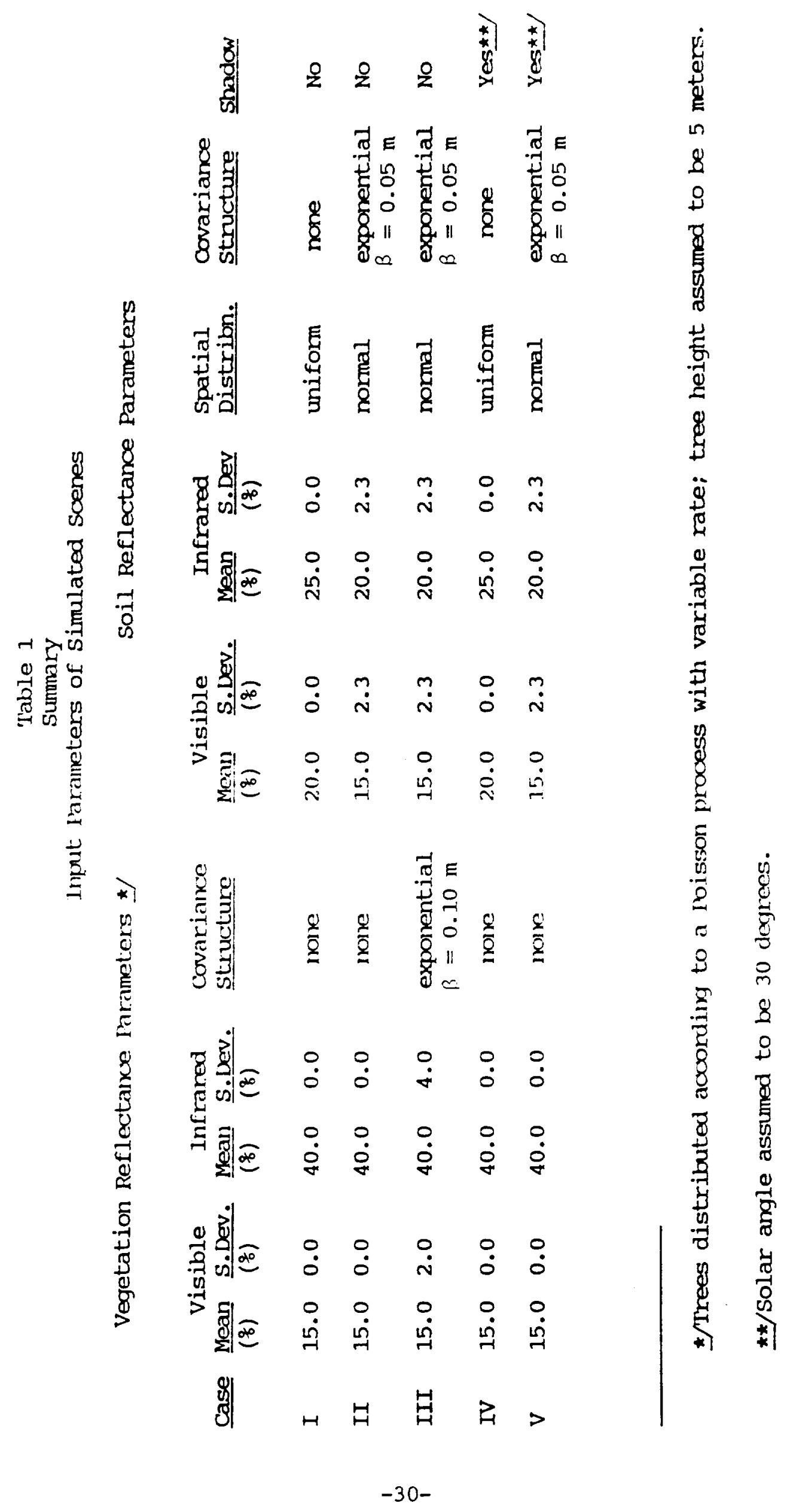


Table 2

\section{Soil Iine Parameters of Pecan Orchard}

\author{
Red TM Band \\ $(0.62-0.69 \mathrm{~lm})$
}

Infrared TM Band

$(0.78-0.90(\mathrm{~mm})$
Mean Reflectance $(q)$
27.3
32.8
Standard Deviation
of Reflectance $(\%)$
3.7
4.1
Soil Iine Equation $(\%): \quad R_{g_{I}}\left(\lambda_{I R}\right)=1.09 R_{g_{I}}\left(\lambda_{R E D}\right)+3.06$
Covariance Iength Scaie 2200 meters 
Table 3

Comparison of Actual and Hypothetical

Fractional covers for

Pecan Orchard

\begin{tabular}{ll} 
Total & Total \\
Canopy & Shadowed \\
Cover & Soil cover \\
(q) & $(q)$ \\
\hline
\end{tabular}

Total

Illuminated

soil cover

(\%)

Pixel

Number

\begin{tabular}{|c|c|c|c|c|c|c|}
\hline & Actual & Model & Actual & Model & Actual & Model \\
\hline 1 & 55 & 54 & 35 & 29 & 10 & 17 \\
\hline 2 & 50 & 51 & 30 & 29 & 20 & 20 \\
\hline 3 & 15 & 21 & 11 & 25 & 74 & 54 \\
\hline 4 & 19 & 20 & 12 & 24 & 69 & 56 \\
\hline
\end{tabular}




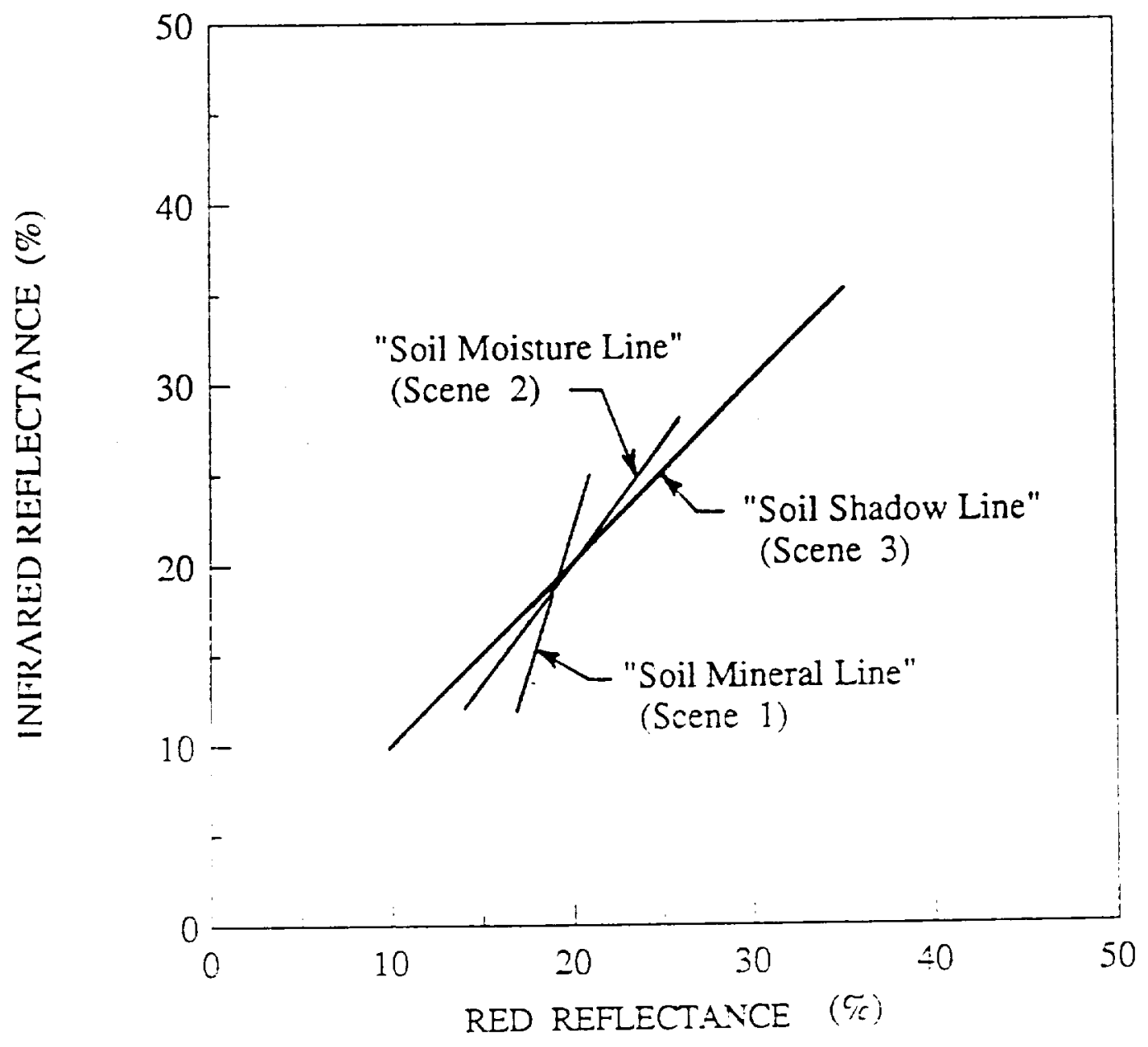

Figure 1. Hypothetical soil lines. 


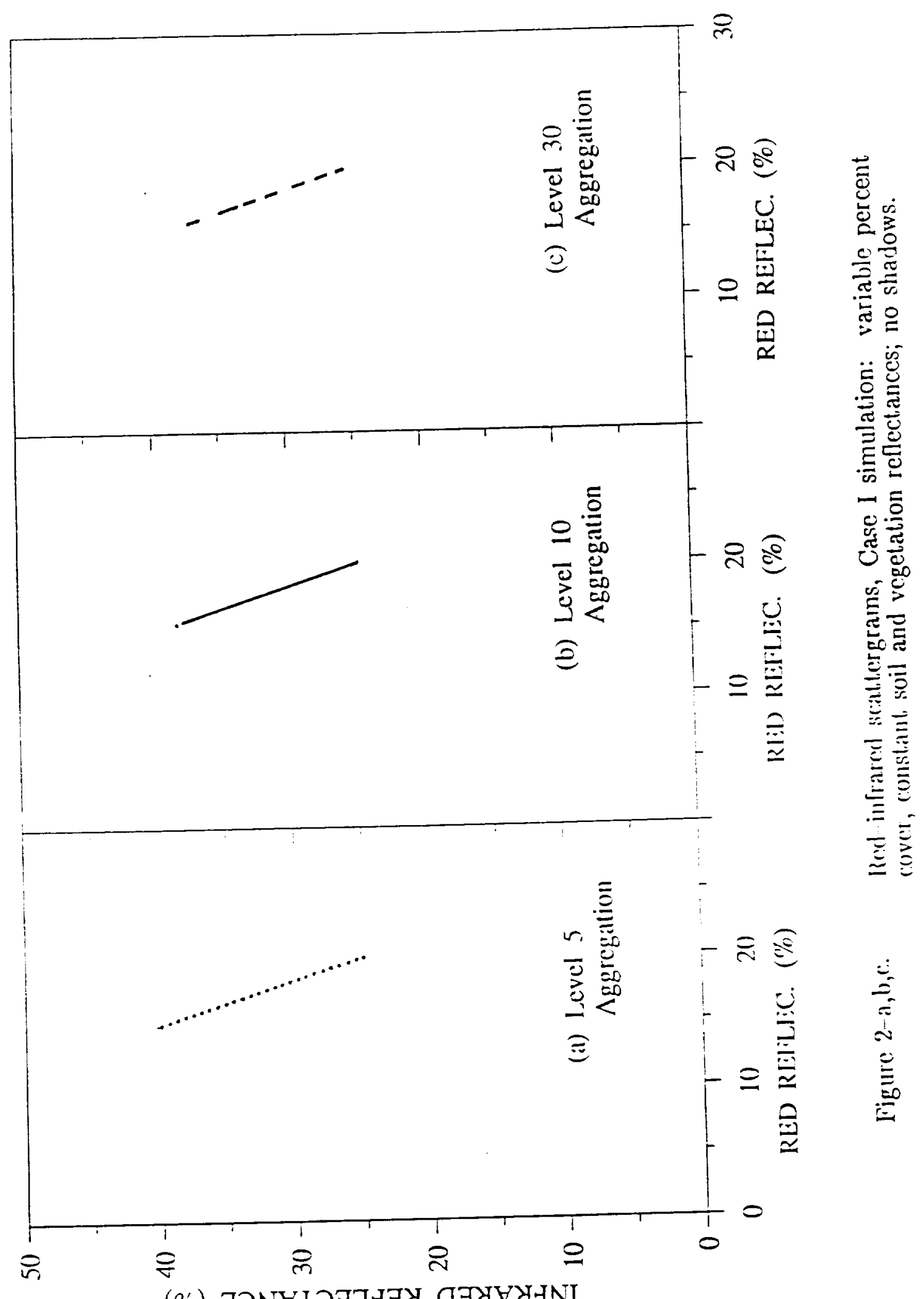

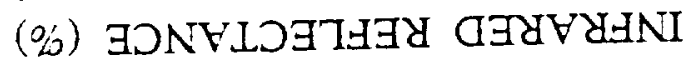




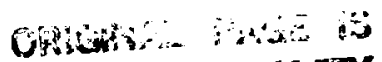 \\ OF POOR QUALITY}

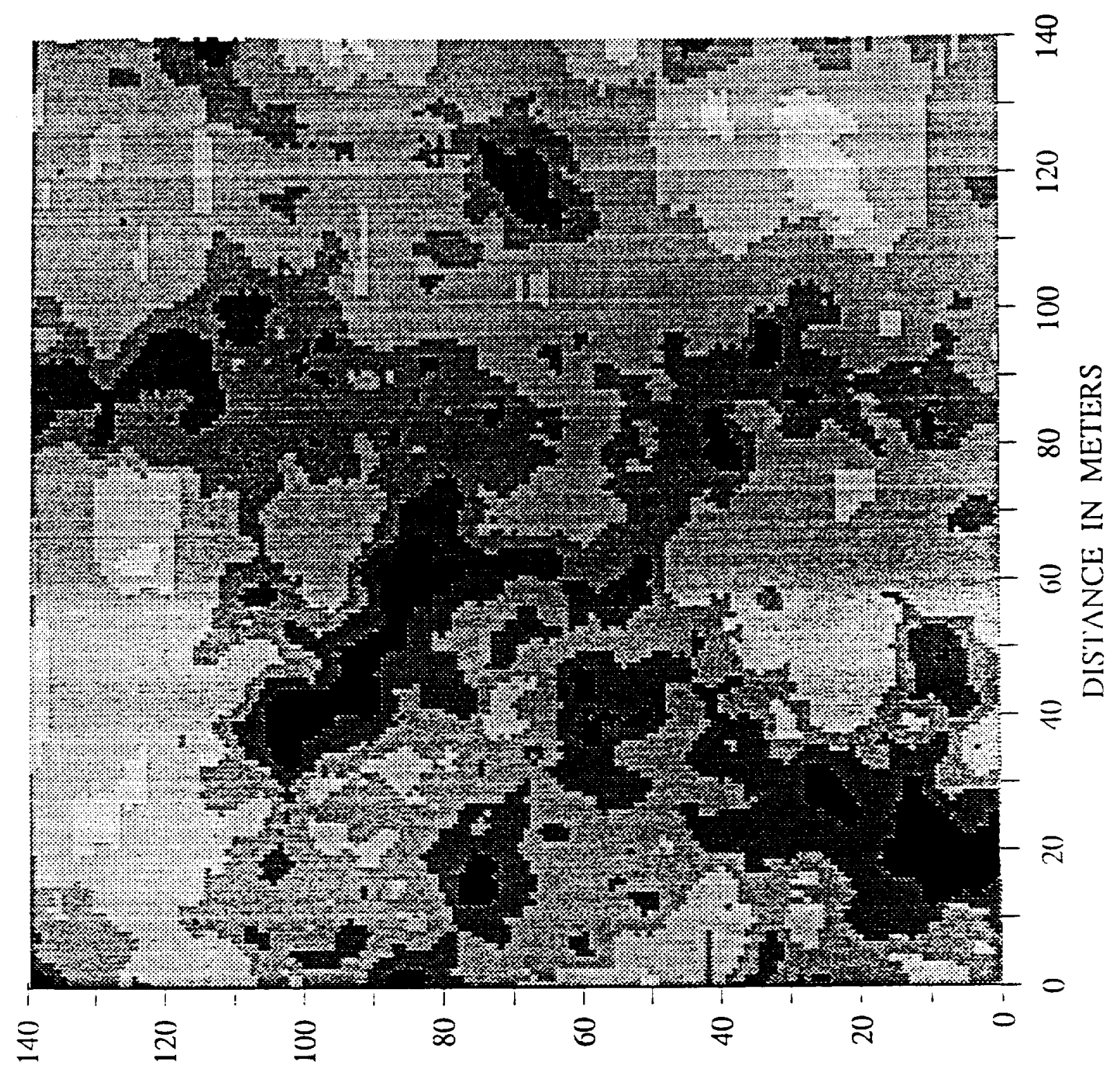

$\frac{\stackrel{5}{3}}{\frac{0}{0}}$

ฮ્

$\overline{5}$

怘

5

离

SУĲWN NI BONVLSIC 


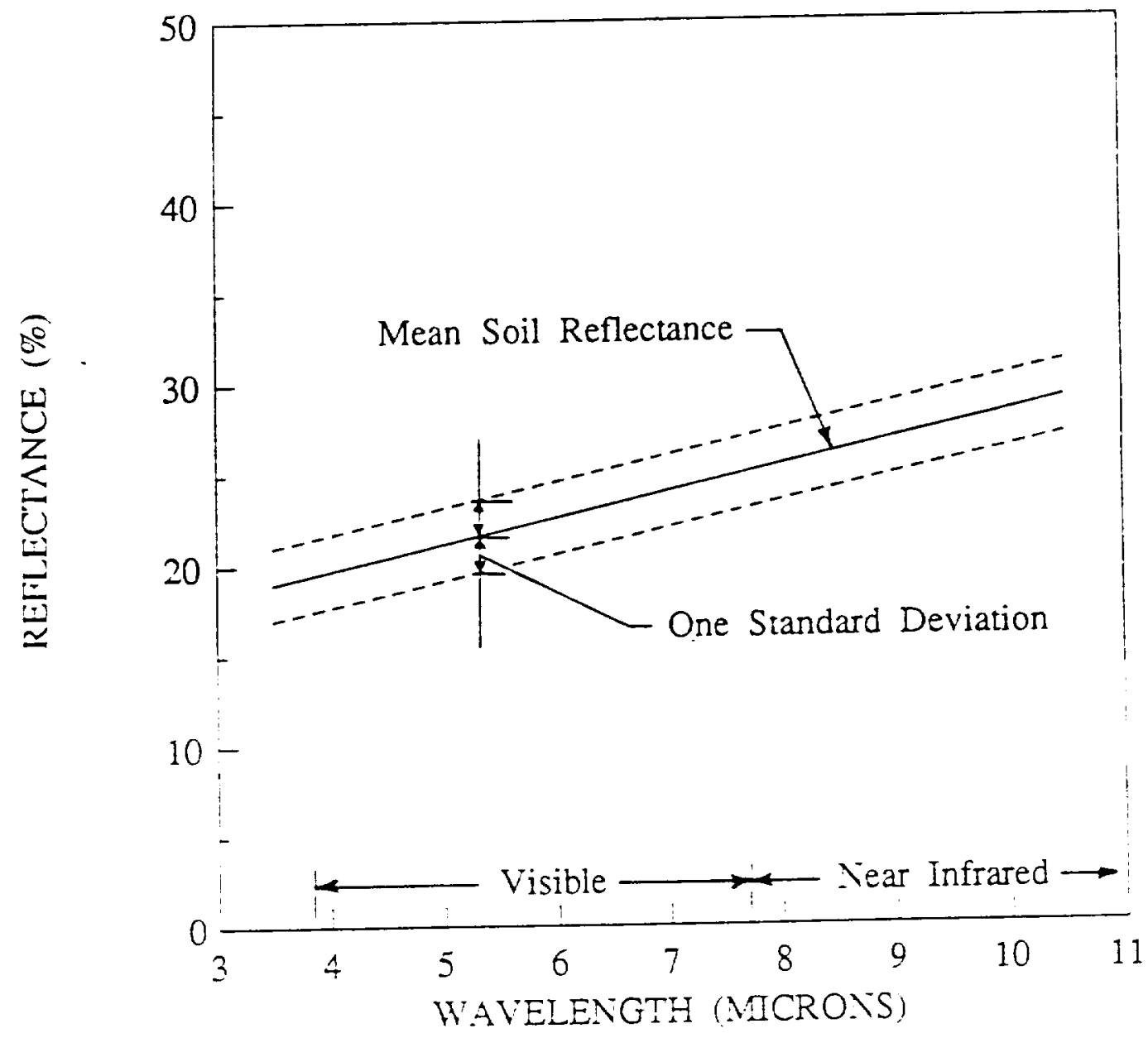

Figure 4. Hypothetical soil reflectance curve. 


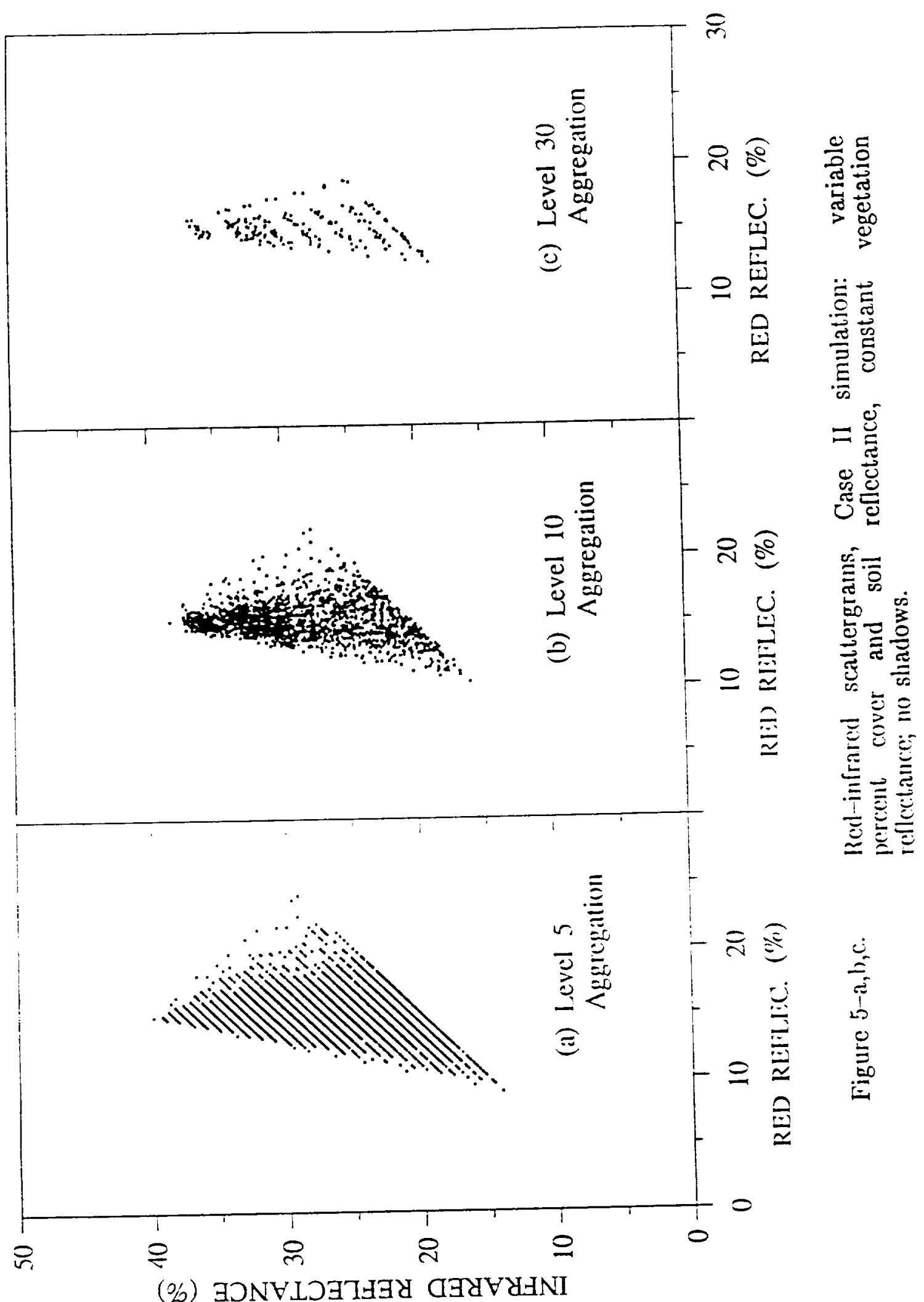




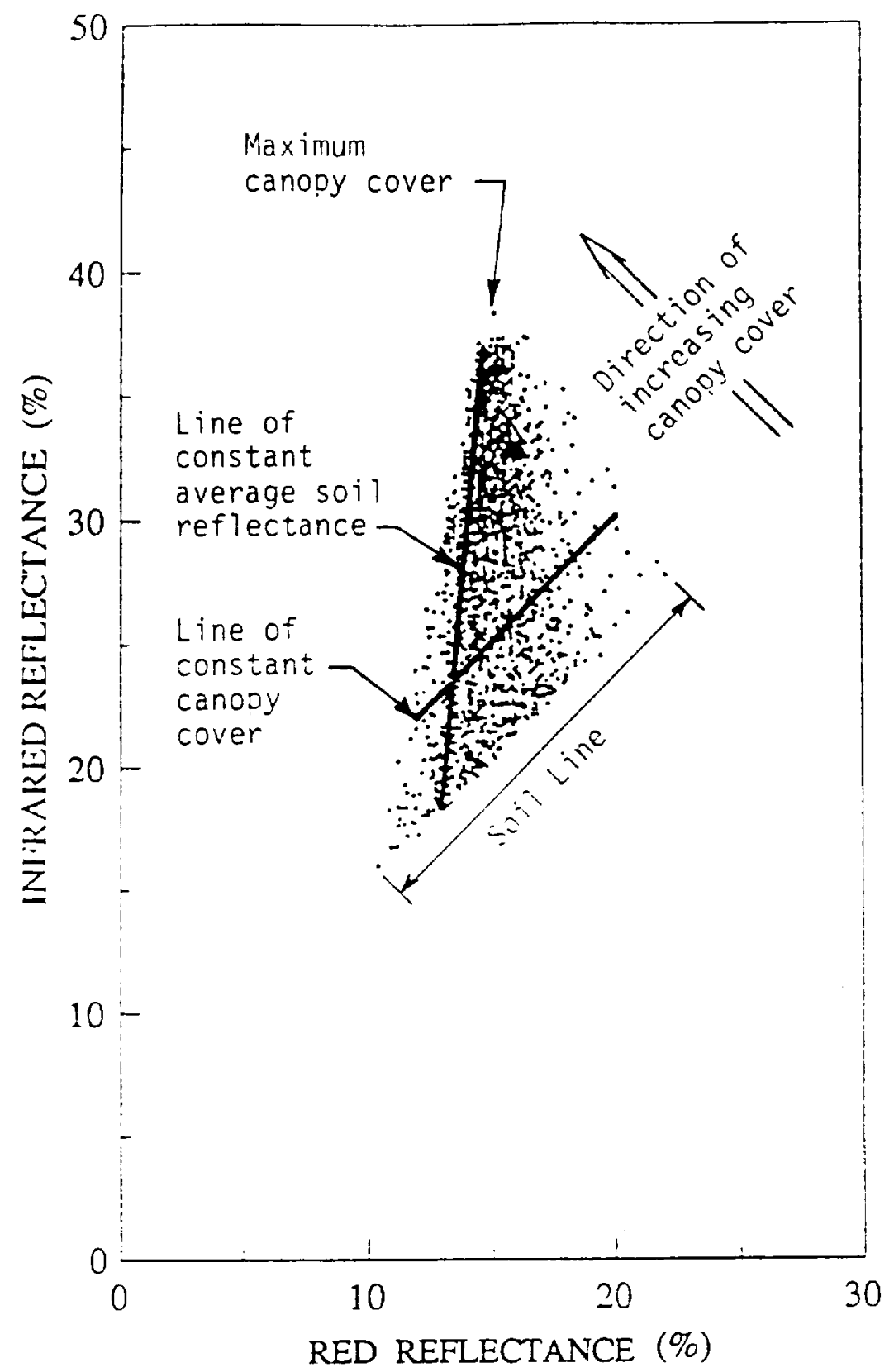

Figure 6. Interpretation of scattergram, Case II simulation, level 10 aggregation: variable percent cover and soil reflectance, constant vegetation reflectance; no shadows. 


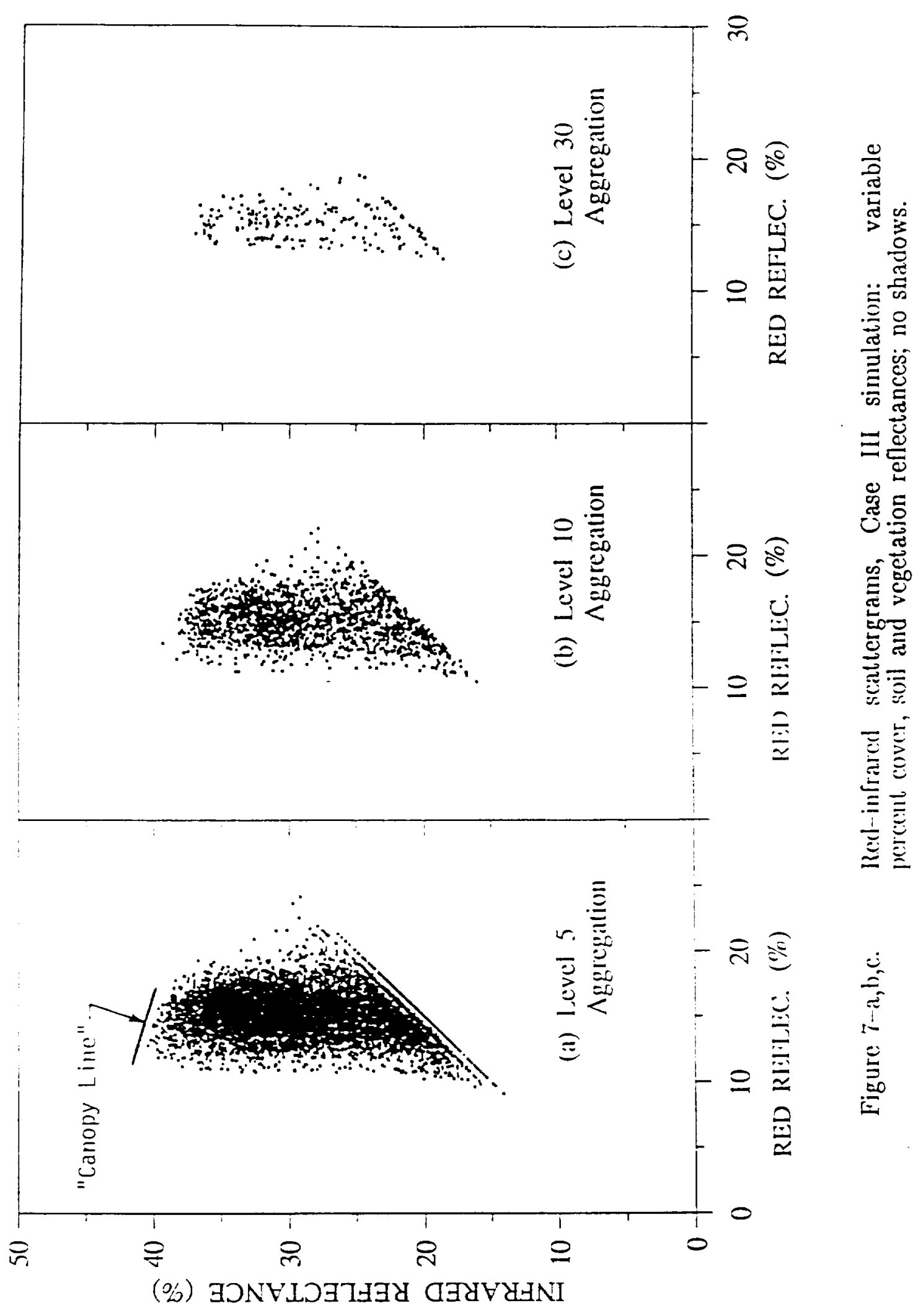




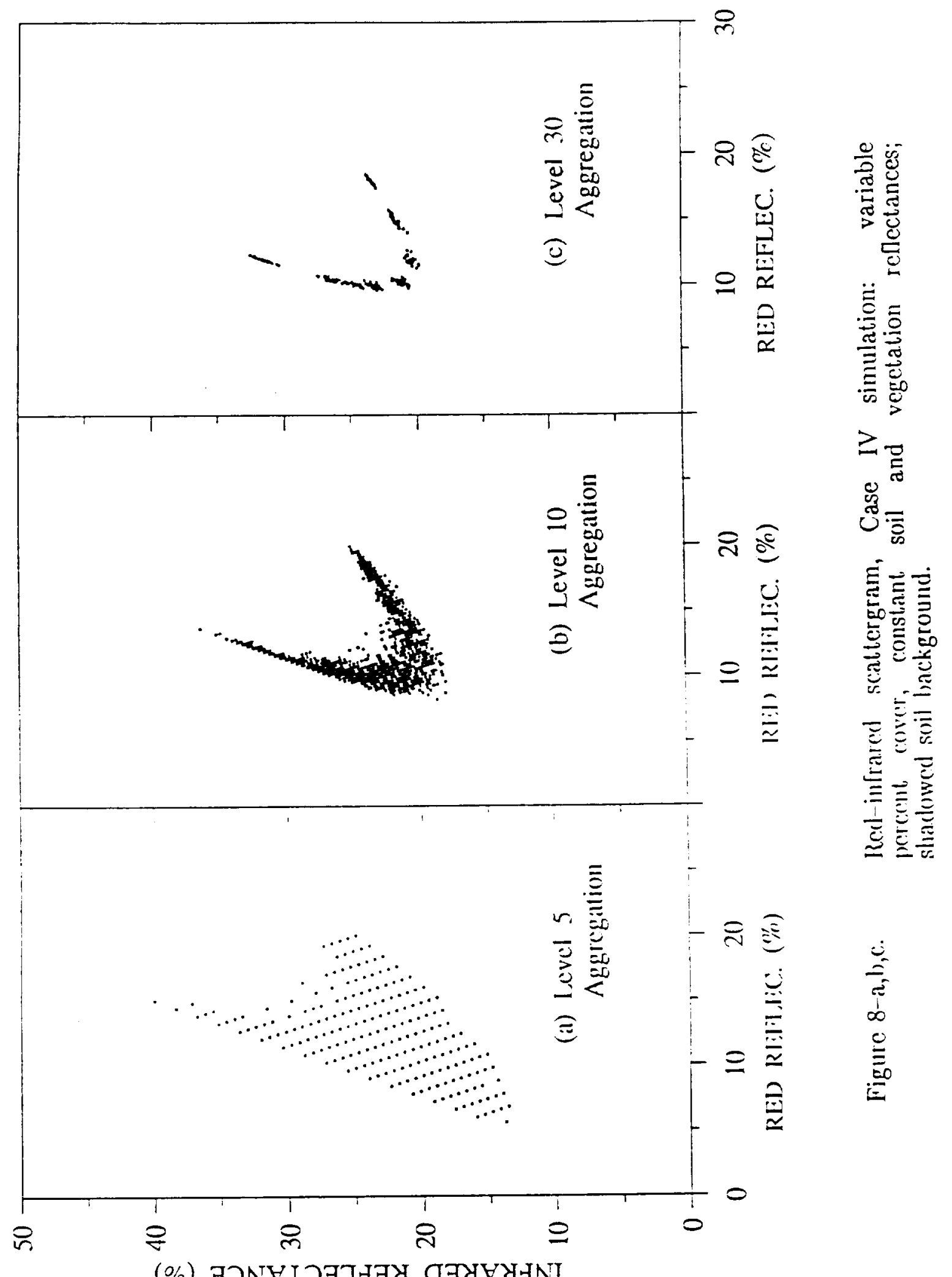




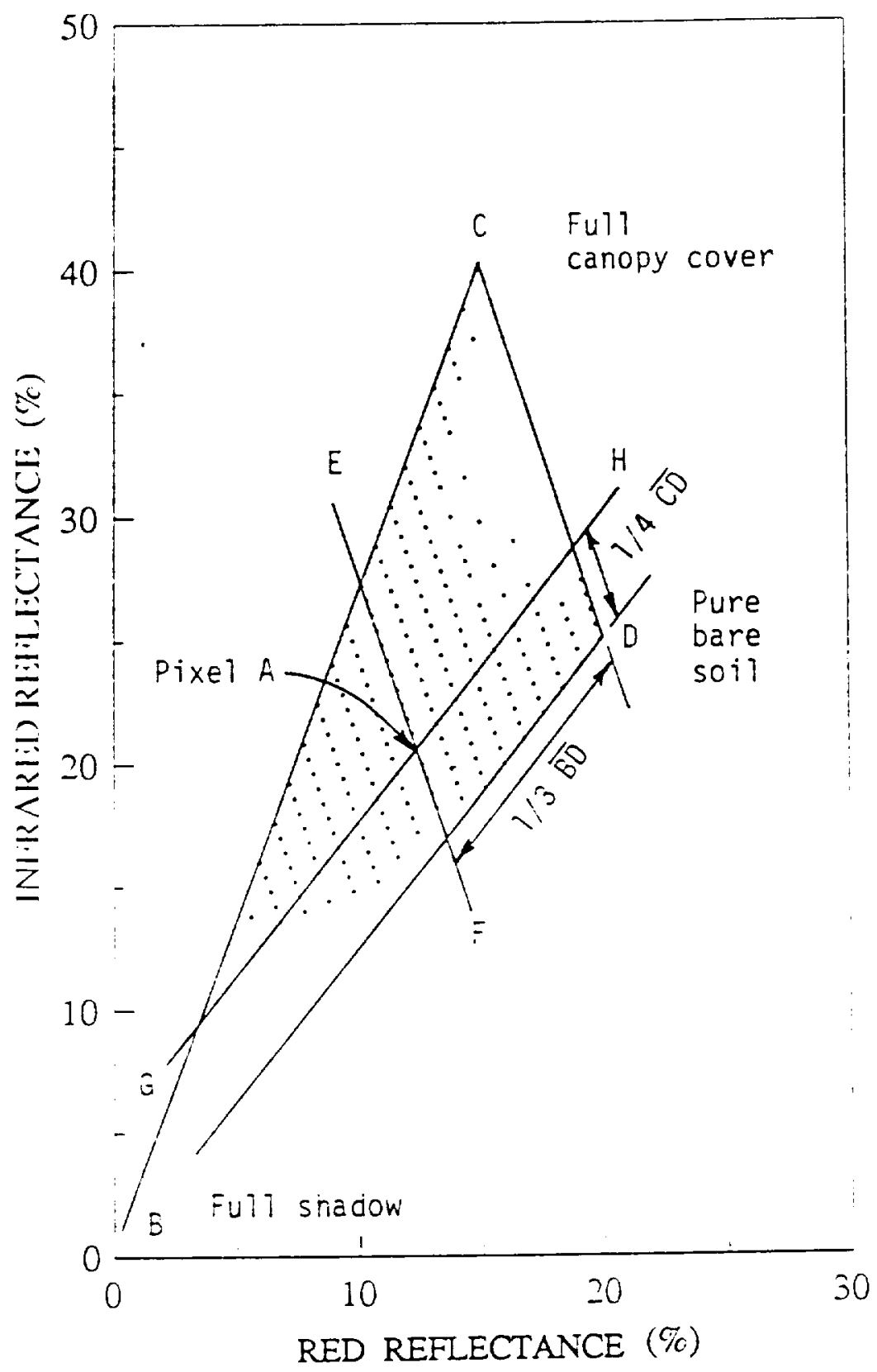

Figure 9. Interpretation of scattergram, Case IV simulation, level 5 aggregation: variable percent cover, constant soil and vegetation reflectances; shadowed soil background. 


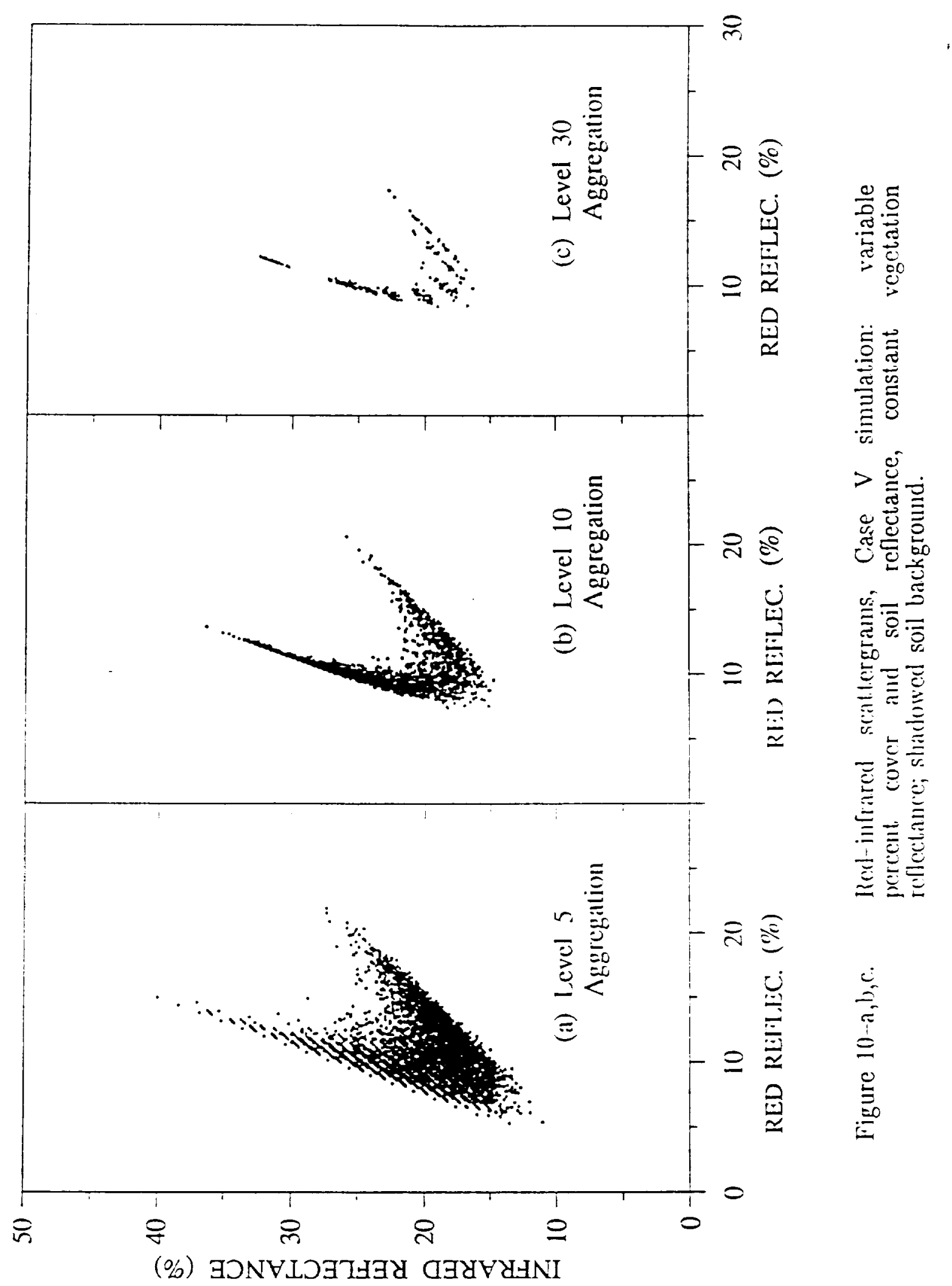




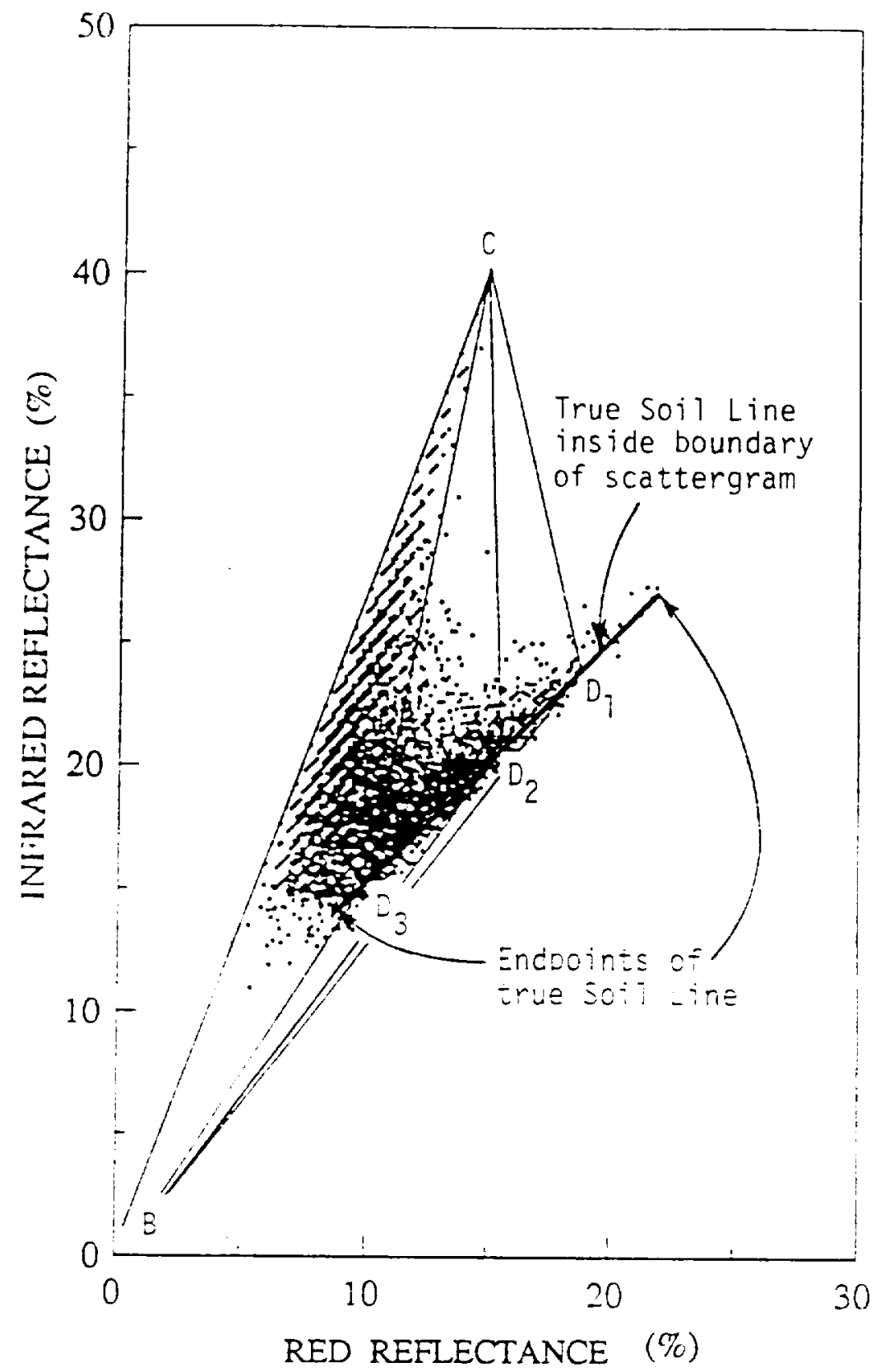

Figure 11. Interpretation of scattergram, Case $\mathrm{V}$ simulation, level 5 aggregation: variable percent cover and soil reflectances, constant vegetation reflectance; shadowed soil background. 


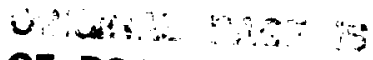

OF. POCR QUALITY

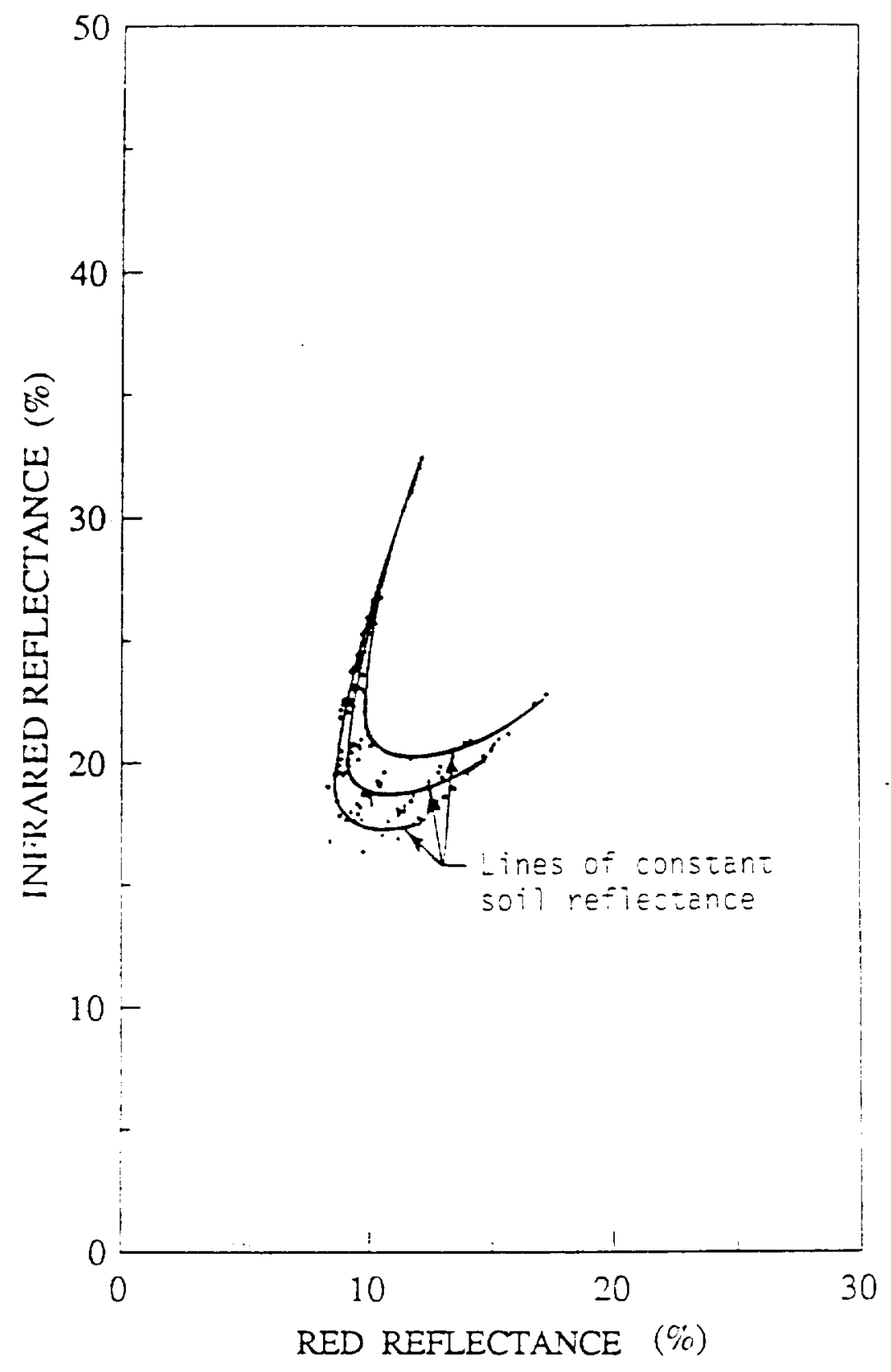

Figure 12. Interpretation of scattergram, Case V simulation, level 30 aggregation: variable percent cover and soil reflectance, constant vegetation reflectance; shadowed soil background. 


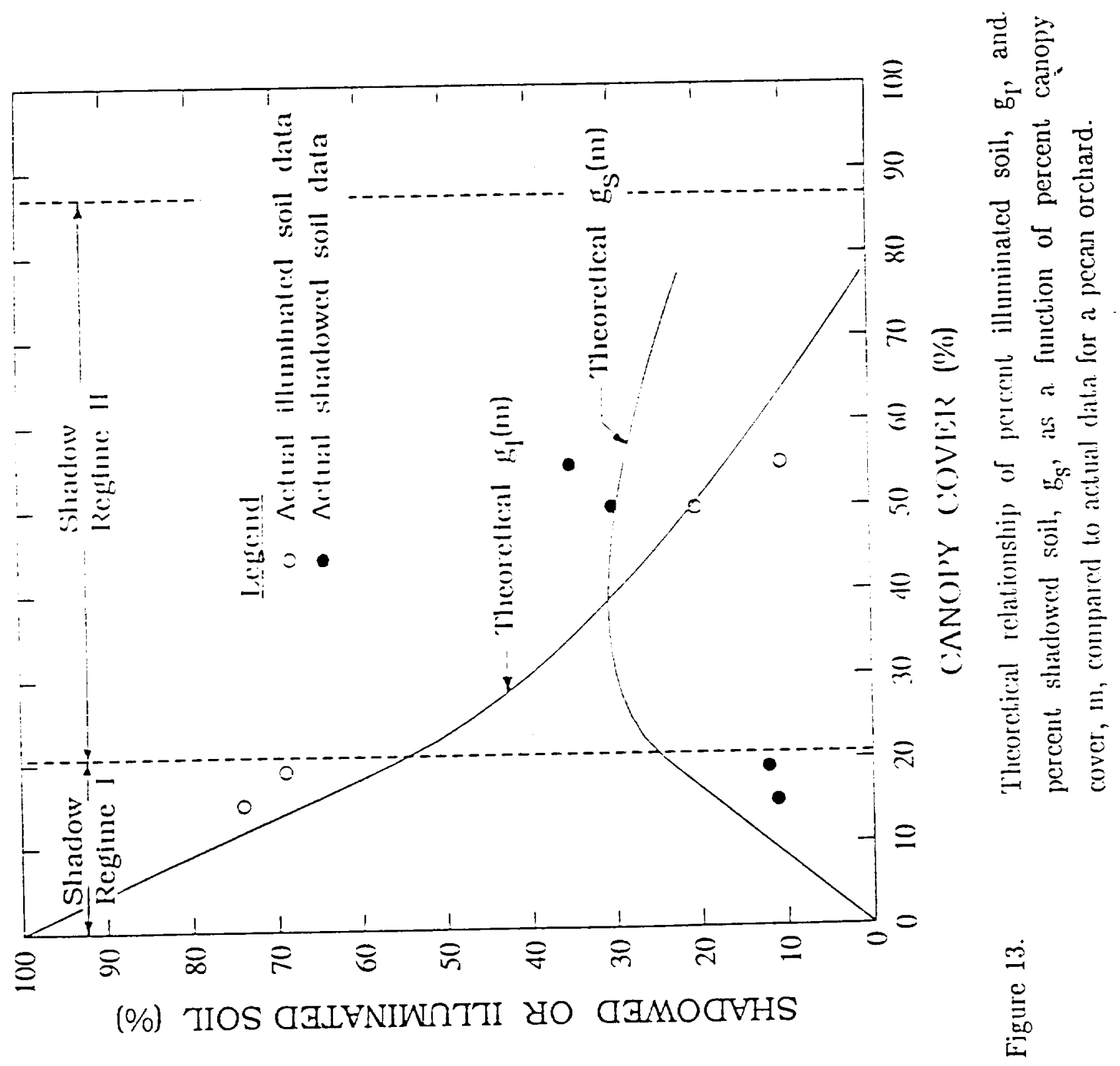


OF POU QUALITY

$\frac{5}{3}$

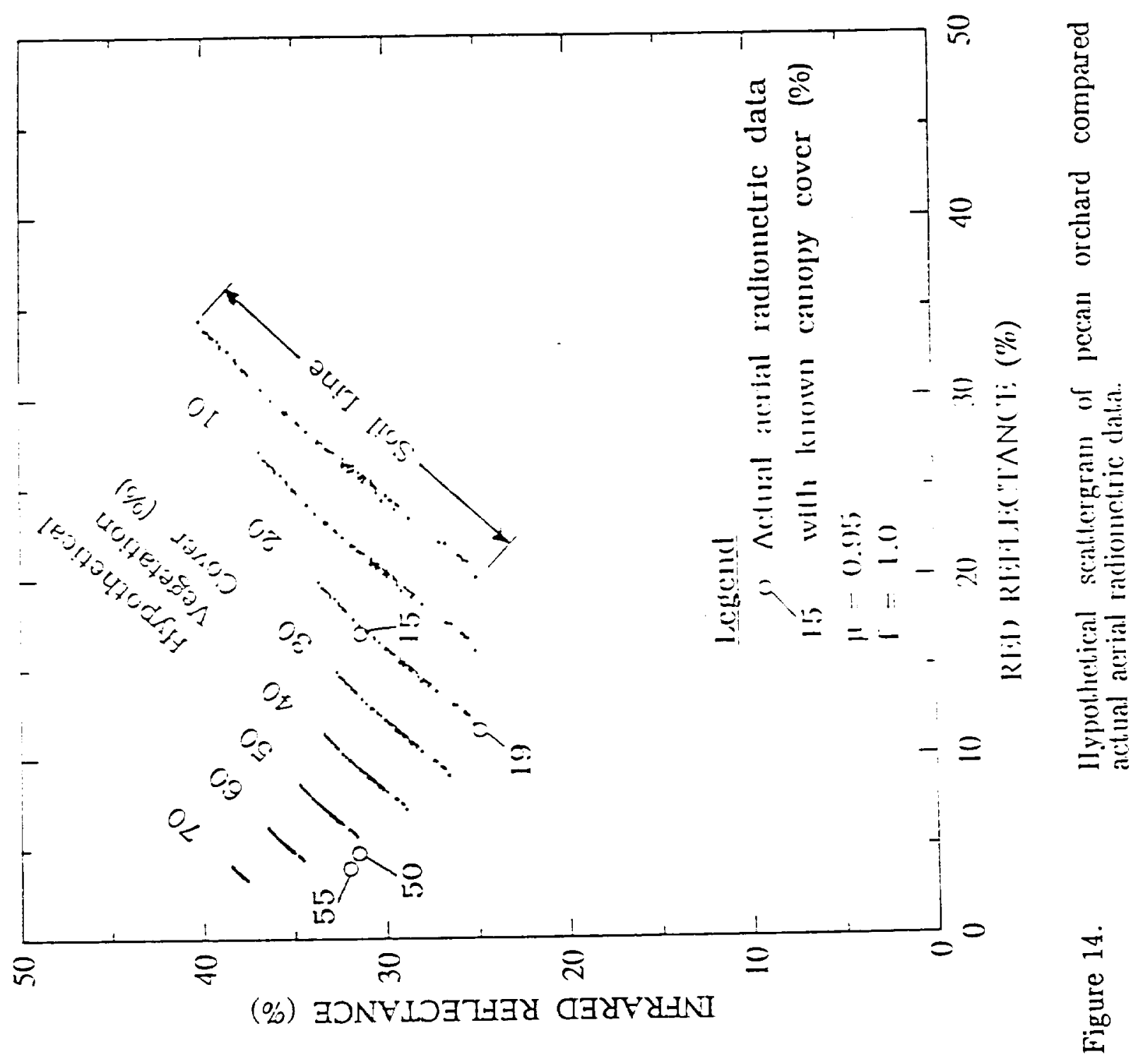

